\title{
Annexin A2 and cancer: A systematic review
}

\author{
MARIA V. CHRISTENSEN ${ }^{1}$, CLAUS K. HØGDALL ${ }^{2}$, \\ KIRSTEN M. JOCHUMSEN ${ }^{3}$ and ESTRID V.S. HØGDALL ${ }^{1}$
}

\author{
${ }^{1}$ Department of Pathology, Molecular Unit, Herlev Hospital, University of Copenhagen, Copenhagen; \\ ${ }^{2}$ Department of Gynaecology, Juliane Maria Centre (JMC), Rigshospitalet, University of Copenhagen, \\ Copenhagen; ${ }^{3}$ Department of Gynaecology and Obstetrics, Odense University Hospital, Odense, Denmark
}

Received August 23, 2017; Accepted October 10, 2017

DOI: 10.3892/ijo.2017.4197

\begin{abstract}
Annexin A2 is a 36-kDa protein interfering with multiple cellular processes especially in cancer progression. The present review aimed to show the relations between Annexin A2 and cancer. A systematic search for studies investigating cancer and Annexin A2 expression was conducted using PubMed. Acute lymphoblastic leukaemia, acute promyelocytic leukaemia, clear cell renal cell carcinoma, breast, cervical, colorectal, endometrial, gastric cancer, glioblastoma, hepatocellular carcinoma, lung, multiple myeloma, oesophageal squamous cell carcinoma, ovarian cancer, pancreatic duct adenocarcinoma, prostate cancer and urothelial carcinoma were evaluated. Annexin A2 expression correlates with resistance to treatment, binding to the bone marrow, histological grade and type, TNM-stage and shortened overall survival. The regulation of Annexin A2 is of interest due to its potential as target for a more individualized cancer management.
\end{abstract}

\section{Contents}

1. Introduction

2. Background

3. Overview of the publications

4. Discussion

5. Conclusion

\section{Introduction}

In order to individualize treatment of cancer patients, there is a growing need to characterize different cancer subgroups. More knowledge on cancer subtypes could improve both prognosis and treatment.

Correspondence to: Professor Estrid V.S. Høgdall, Department of Pathology, Molecular Unit, Herlev University Hospital, Herlev Ringvej 75, 2730 Herlev, Denmark

E-mail: estrid.hoegdall@regionh.dk

Key words: Annexin A2, S100, cancer, methodologies, tumour markers, tissue expression
The protein Annexin A2 has been investigated as a prognostic marker because of its widespread presentation in several cancer forms. This study takes an overview of Annexin A2 and its presentation in various cancers including its prognostic values and potential as therapeutic target.

\section{Background}

Annexin A2 is part of the Annexin family consisting of up to 160 unique Annexin proteins (1). There are two criteria for being an Annexin protein. The first criterion is the ability to bind negatively charged phospholipid in a calcium-dependent manner. Second is the structural containment of an Annexin repeat, a segment of 70 amino acid residues. Annexin proteins comprise four or eight Annexin repeats and an $\alpha$-helix disc (1). These folds allow Annexin to move intracellularly between lipofobic cytosol and lipophilic membrane compartment in a calcium-dependent manner (2).

Annexin proteins consist of three domains: a divergent $\mathrm{NH}_{2}$-terminal, a $\mathrm{C}$-terminal and a preserved domain making the core of the protein $(1,3)$. For Annexin A2 the $\mathrm{NH} 2$-terminal acts as a binding site for S100A10 and tissue plasminogen activator (t-Pa). The core binds to calcium and the cell membrane. The $\mathrm{C}$-terminal contains the binding site for F-actin (4), heparin (5) and plasminogen (6). The substrates for Annexin A2 reveal its function as an intercellular transport protein, interactor in cell division and migration and main interactor in plasmin production.

Intracellular Annexin A2. Free cytoplasmic Annexin A2 exists as a $36-\mathrm{kDa}$ protein (1). Intracellularly, Annexin A2 is involved in exocytosis $(7)$, endocytosis $(7,8)$ and membrane trafficking through lipid micro-domains (9). Knockdown of the Annexin A2 gene, ANXA2, has been shown to diminish DNA synthesis and cell proliferation, suggesting that Annexin A2 is a factor in cell division (10). Furthermore, an interaction between Annexin A2 and CD44 has been shown to be essential for the formation of lipid rafts that interact with the cellular cytoskeleton (11). A complex of Annexin A2 and S100A10 directly binds F-actin at cholesterol-rich membrane passages, thereby interacting with the cytoskeleton (1). It has been shown that ANXA2 interacts in p53-mediated apoptosis (12) and prevents radiation-induced apoptosis, the latter by activating pro-survival signals such as nuclear factor $\kappa \mathrm{B}(13)$. Annexin A2 
also inhibits phospholipase A2 (PLA2) in an endogen manner, acting to inhibit PLA2 induced inflammation (14).

Extracellular and membrane bound Annexin A2. By binding directly or indirectly to phosphatidylserine on cells marked for apoptosis, Annexin A2 attends in the engulfment of cells (15). Membrane bound Annexin A2 contributes to fibrinolysis and has anticoagulation effects and involves binding to t-Pa and S100A10, hereby facilitating plasmin production $(16,17)$. Furthermore, Annexin A2 seems to impact neo-angiogenesis which may explain its effect on solid tumours (17).

\section{Interactions of Annexin A2}

S100A10. S100A10 is part of the S100 protein family being calcium binding proteins of EF-hand type. The S100 family consist of 25 distinct isoforms weighing from 9 to $13 \mathrm{kDa}(18)$. Twenty-two out of $25 \mathrm{~S} 100$ genes are located in the 1q21 chromosome region which is prone to genomic rearrangement. This indication of an unstable region supports how S100 proteins may be a relevant focus in cancer development (18).

The intracellular function of S100A10 includes calcium homeostasis, cell cycle regulation, phosphorylation, cell growth, migration and interactions with cytoskeleton components and regulation of transcriptional factors (18).

The extracellular function of S100 proteins is comparable to a cytokine-like behaviour by binding to cell surface receptors (18). S100A10 is seen to play a critical role in angiogenesis in vivo, suggesting its role in endothelial cell function (18).

S100A10 is unique in its way of being locked in a permanently open conformation (19). The binding of Annexin A2 is accommodated in the free hydrophobic space between Helix III and IV of the S100A10 dimer (19). In the cell membrane, Annexin A2 combines with S100A10 forming a $94 \mathrm{kDa}$ heterotetramer of two Annexin A2 units and two 11-kDa S100A10 proteins. The Annexin A2-S100A10 heterotetramer is a key plasminogen receptor that on the cell surface mediates the formation of plasmin. S100A10 furthermore enhance the sensitivity of Annexin A2 to calcium, interfering with the calcium level needed to conduct Annexin A2 function (20). S100A10-Annexin A2 interaction seems to play a role in the cell-to-cell adhesion of breast cancer cells and multiple types of endothelium. Interaction has been shown by investigating the protein expression of Annexin A2 and S100A10 in tissue from breast cancer patients (21).

The plasminogen/plasmin system is interaction between coagulation factors and enzymes. Plasminogen is the inactive form of plasmin found in plasma and extra cellular matrix (ECM). Plasminogen is cleaved by plasminogen activators (tPa) through the hydrolysis of the Arg561-Val562 peptide bond to yield the serine protease, plasmin (22). Plasmin is an enzyme cleaving fibrin in the ECM by direct binding or by activating other proteases (23). Altogether plasminogen/ plasmin/fibrin are important regulators of proteolysis of ECM, fibrin clot degradation, macrophage migration, tissue remodelling, invasion and angiogenesis (22). An overproduction of plasmin in the tumour microenvironment enhance the degradation of ECM, hereby facilitating tumour invasion (22). Annexin A2 has independent binding sites for both $\mathrm{tPa}$ and plasminogen. By assembling these proteins on the cell surface, Annexin A2 accelerates the production of plasmin (22). The binding site between Annexin A2 and tPa are mechanically blocked by lipoprotein(a) and homocysteine which both are arteriothrombotic agents (2). Annexin A2-S100A10 regulates $50-90 \%$ of the plasmin generation in several types of normal cells and cancer cells (24).

Human epididymis protein 4 (HE4). The binding site of HE4 to Annexin A2 is located after the 26th amino acid at the $\mathrm{N}$-terminus (5). HE4 and Annexin A2 activates the extracellular signal-regulated kinase/mitogen-activated protein kinase (ERK/MAPK) and focal adhesion kinase (FAK) pathways (25). The ERK/MAPK signalling pathway influences proliferation, migration and apoptosis (26). FAK is a regulator of cell signalling within the tumour microenvironment and controls cell movement, invasion and survival (27).

Angiostatin (AS). Angiostatin is a 38-kDa internal fragment of plasminogen that interacts through the lysine binding domain on the C-terminus of Annexin A2 on the cell surface (28). This is also the binding site for plasminogen (22). By using AS to compete with plasminogen binding, $\sim 40 \%$ of the binding to bovine arterial endothelium cells were blocked (29).

Human procathepepsin. Procathepepsin B is an enzyme hosted in lysosomes. Procathepepsin B can degrade ECM proteins such as laminin, fibronectin and collagen IV, hereby facilitating invasion of the tumours cells (30). Immunohistochemistry (IHC) showed recombinant procathepsin to interact with the Annexin A2-S100A10 heterotetramer (31). Likewise, it has been shown that procathepepsin and the Annexin A2 heterotetramer co-localize in two lines of human cancer cells, one of epithelial origin and one of mesenchymal origin. Procathepsin B can alone or in interaction with Annexin A2 activate other proteolytic proteins such as urokinase-type plasminogen activator and collagenase. These proteins also degrade ECM and facilitate invasion (30).

Stromal derived factor 1 (SDF1/CXCL-12). Multiple myeloma, breast and prostate cancer are known to metastasize to the bone marrow (32) causing distinct pain and sometimes neural complications for the patients. In vivo and in vitro studies have showed how Annexin A2 and CXCL-12 co-localize in the bone marrow. Studies using whole bone marrow cells and investigating the migration of hematopoietic stem cells (HSC) demonstrated a synergistic effect of CXCL-12 bound to Annexin A2 (33). Expression of Annexin A2 in bone marrow stromal cells (BMSC) significantly increased the binding of prostate cancer (PC) cells to BMSC (34). Furthermore, studies demonstrated how CXCL-21 expression induced the migration of PC cells towards BMSC (34). Multiple myeloma cells also express Annexin A2. It was demonstrated how this Annexin A2 expression facilitated the adhesion of osteoblasts and stromal cells in the bone marrow (35).

Functional regulation of Annexin A2. The N-terminus of Annexin A2 is regulated by phosphorylation. Annexin A2 and S100A10 form their heterotetramer on the cell surface in response to changes in intracellular (ICL) calcium concentration (2). This presentation on the surface can be provoked by heat induced stress of the cell. By using small interfering 


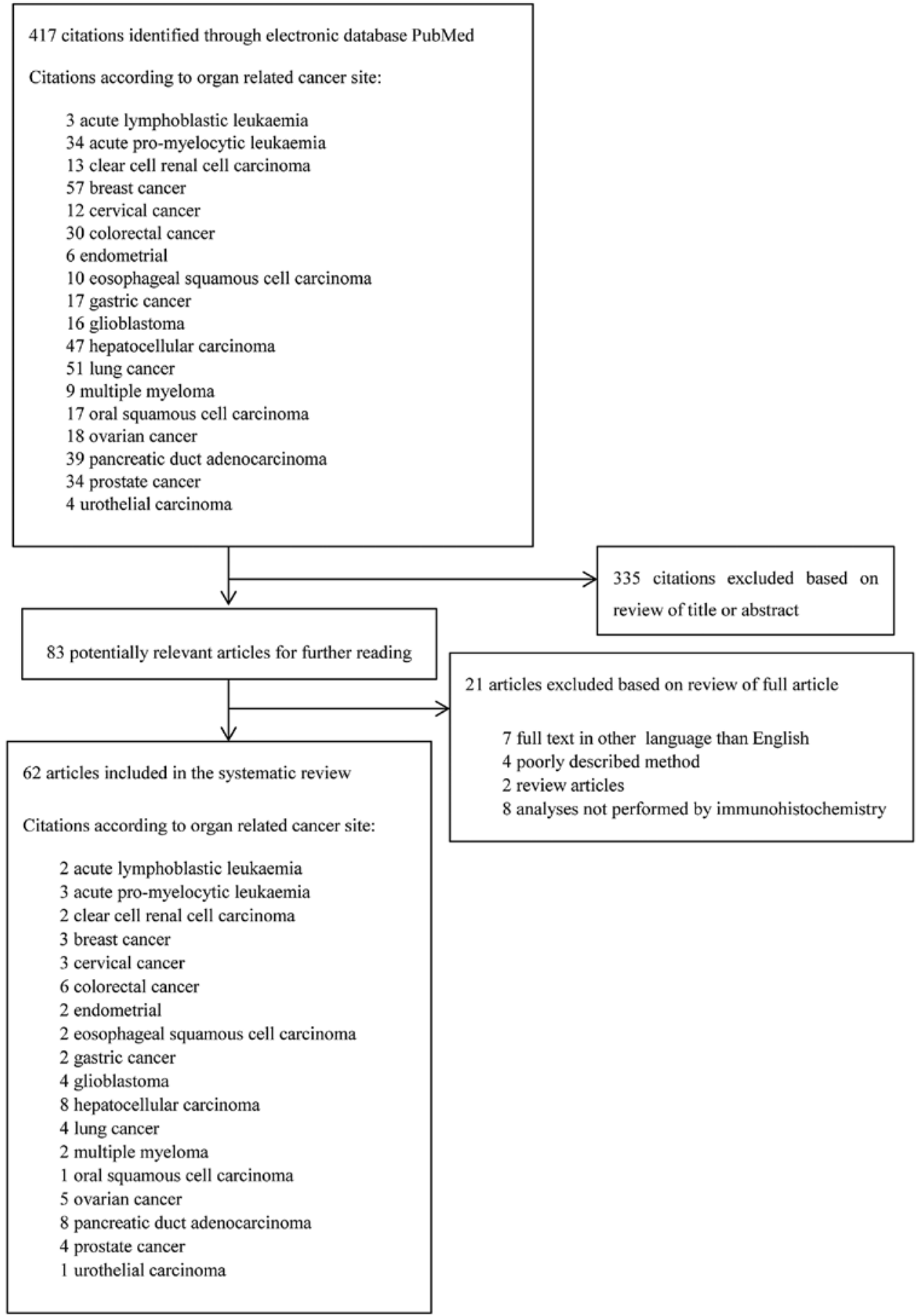

Figure 1. Flow diagram of the literature search in PubMed database. The keywords: 'the organ related cancer site' and 'Annexin A2' was used. A total of 62 articles published from 1990-2016 were included.

RNAs (siRNA), targeting S100A10, it was demonstrated that by reducing S100A10 expression, the heat stimulated translocation of Annexin A2 was markedly reduced (2). This shows how S100A10 is essential to the translocation of Annexin A2 caused by mild cellular stress (2).

Phosphorylation of Annexin A2 at residue 23 by src-like tyrosine kinases plays a role in the translocation of Annexin A2 to the cell surface (2). By using tyrosine kinase inhibitors, the heat stress induced expression of Annexin A2 on the cell surface was completely blocked demonstrating how tyrosine kinase phosphorylation of tyrosine 23 in Annexin A2 is essential to the translocation to the cell surface (2). Furthermore, protein kinase $\mathrm{C}$ (PKC) combined with calcium phosphorylates Annexin A2. This can be inhibited by Annexin A5 by interaction with PKC and diminishing its effect thereby reducing Annexin A2 translocation. Annexin A5 might have a therapeutic function in preventing Annexin A2s adverse function in cancer development.

Method. Initial search in PubMed database was made February 6,2017 (Fig. 1). The following search criteria 'the organ related cancer site' and 'Annexin A2' was used. The search was combined with a screening for literature in reference sections of relevant studies. For preliminary screening of the articles, 
all titles and abstracts were read. A total of 62 studies were included in the review and included studies were published from 1990-2016.

\section{Overview of the publications}

Annexin A2 is overexpressed in clear cell renal cell carcinoma, breast-, cervical-, colorectal-, endometrial-, gastric cancer, hepatocellular carcinoma, lung- and ovarian cancer, pancreatic duct adenocarcinoma, glioblastoma and urothelial carcinoma, acute lymphoblastic leukaemia, acute promyelocytic leukaemia and multiple myeloma (36-86).

Downregulation of Annexin A2 is reported in oesophageal squamous cell carcinoma $(88,89)$.

Both upregulation and downregulation of Annexin A2 have been suggested as prognostic markers for patients diagnosed with oral squamous cell carcinoma (90) and prostate cancer (34,91-93). In Table I an overview of the relationship between Annexin A2 and different cancers is presented.

\section{Haematological cancers}

Acute lymphoblastic leukaemia (ALL). In patients with ALL, elevated levels of ANXA2 and increased amounts of phosphorylated Annexin A2 relate to resistance to glucocorticoid treatment (36). Annexin A2 is phosphorylated by Src-kinase, the reaction is facilitated by S100A10 (37). Elevated Annexin A2, S100A10 and Src-kinase activity may predict drug resistance in ALL patients $(36,37)$. By inhibiting the Src-kinase, the ALL cells were sensitised to glucocorticoid treatment suggesting that Src-kinase inhibitors might be a supplement to treatment of glucocorticoid resistant ALL patients (36). Treatment of ALL cells with anti-Annexin A2 antibody and knockdown of S100A10 abrogate ALL adhesion to osteoblasts (37). This inhibition of ALL cell adhesion to osteoblasts indicates how Annexin A2 and S100A10 influence the binding and retention of ALL cells to the bone marrow (37). Additionally, long-term engraftment assays from mice showed reduced percentage of ALL cells in blood, spleen and bone marrow if treated with agents that disrupts the Annexin A2-S100A10 interaction (37). Furthermore, using mouse monoclonal antibodies against Annexin A2 increased the effect of treatment of ALL with dexamethasone and vincristine by disruption of the binding between ALL cells and osteoblasts (37).

Acute promyelocytic leukaemia (APL). Overexpression of Annexin A2 in APL cells is thought to be the mechanism behind haemorrhagic complications of APL patients $(38,39)$. The $\mathrm{t}(15 ; 17)$ translocation positive APL cells express Annexin A2 in a greater manner than other leukaemia cells (38). Annexin A2 facilitates the combining of $\mathrm{t}-\mathrm{Pa}$ and plasminogen on the cell surface. APL cells with $\mathrm{t}(15 ; 17)$ translocation had twice as effective t-Pa dependent plasmin generation. Annexin A2 overexpression might be the mechanism for haemorrhagic complications of APL patients $(38,39)$. By treating APL cells with siRNA targeting Annexin A2, a decreased t-Pa mediated plasmin generation have been shown (39). Furthermore, APL cells treated with all-trans retinoic acid (ATRA) showed downregulation of Annexin A2. These findings indicate that treatment with siRNA targeting Annexin A2 or ATRA could resolve hyperfibrinolysis in APL $(39,40)$.
Multiple myeloma (MM). Annexin A2 is expressed in MM cells in 8/8 patients (35). Annexin A2 has been shown to stimulate proliferation of MM cells and to support adhesion of MM cells to osteoblasts and stromal cells (35). Other studies, suggest that siRNA silencing of Annexin A2 can induce apoptosis in MM cell lines. Furthermore, by silencing Annexin A2 the invasive potential of MM cells were significantly diminished (74). This makes siRNA targeting Annexin A2 as a potential therapeutic focus to induce apoptosis of MM cells and interfere with the invasive potential (74).

\section{Urological cancers}

Clear cell renal cell carcinoma (ccRCC). Annexin A2 is expressed mainly in the membrane of ccRCC and the amount of Annexin A2 in ccRCC was higher compared to normal tissue (41). In primary ccRCC tumours, the expression of Annexin A2 was positively associated with a higher TNM-stage $(\mathrm{P}<0.05)(41,42)$, histological grade $(\mathrm{P}<0.05)(41)$, infiltration of the renal capsule $(\mathrm{P}<0.01)(41)$ and metastatic potential $(\mathrm{P}<0.01)(41,42)$. Furthermore, Annexin A2 overexpression was significantly correlated with shortened 5-year survival rate of ccRCC patients compared to patients with lower expression of Annexin A2 ( $\mathrm{P}<0.01)(41)$.

Urothelial cancer. Higher Annexin A2 expression is reported in urothelial carcinoma $(55 \%, 175 / 315)$ compared to overexpression in $17.5 \%(11 / 63)$ of the non-tumour mucosa samples $(\mathrm{P}<0.01)(87)$. The expression of Annexin A2 was associated with the depth of invasion, lymph node metastasis and distant metastasis $(\mathrm{P}<0.05)$. Furthermore, Annexin A2 expression is a significant independent prognostic factor for survival among urothelial carcinoma patients $(\mathrm{P}=0.012)(87)$.

Prostate cancer $(P C)$. Annexin A2 is localized primarily in the membrane and faintly in the cytoplasm on PC cells (91). The expression level of Annexin A2 was significantly lower in the PC cases when compared to patients with benign prostate hyperplasia $(\mathrm{P}<0.01)(92,93)$. Lower Annexin A2 expression was negatively related to Gleason score 5-7, tumour stage, recurrence, lymph node metastasis and distant metastasis $\mathrm{P}<0.01$ (92). Additionally, survival rate was significantly correlated to a downregulation of Annexin A2 expression $(\mathrm{P}<0.01)(92)$.

Annexin A2 expression seems to play a critical role in the homing and adhesion of PC cells to the bone marrow (34). Furthermore, it is demonstrated how Annexin A2 in bone marrow stromal cells could play a role in the resistance of PC cells to chemotherapy (34). Although low expression of Annexin A2 correlated to Gleason score 5-7, a strong and diffuse staining of Annexin A2 was seen in PC biopsies indicating an association between Annexin A2 and the most severe PC subtypes (91).

Breast cancer. No expression of Annexin A2 is found in normal or hyperplastic ductal epithelial cells of the human mammarian tissue. On the contrary, protein expression of Annexin A2 is found in breast cancer and ductal carcinoma in situ (CIS) (43). Correspondingly, Annexin A2 has been shown to be upregulated in HER-2 negative and herceptin resistant breast cancer cells (44). Annexin A2s ability to stimu- 


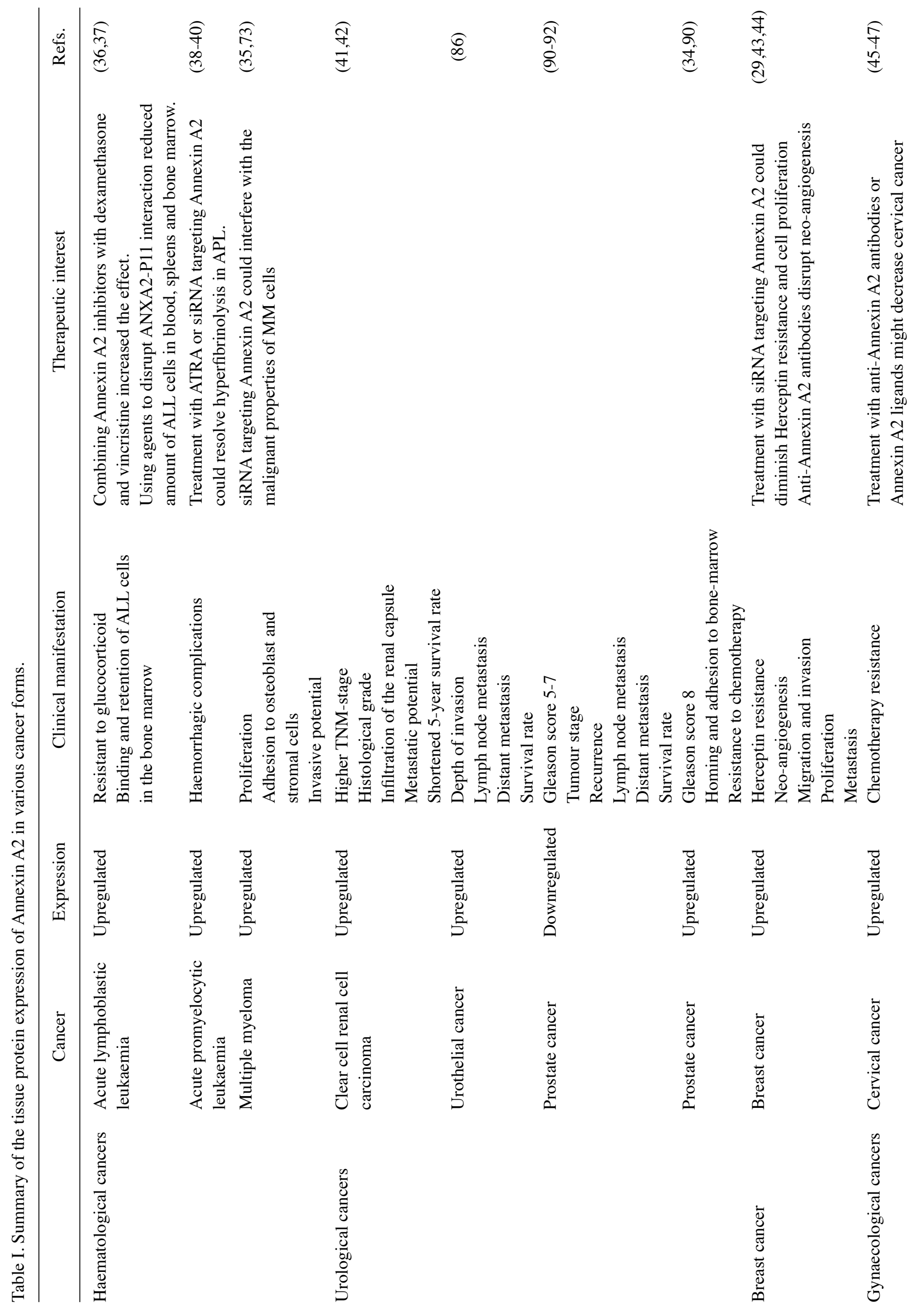




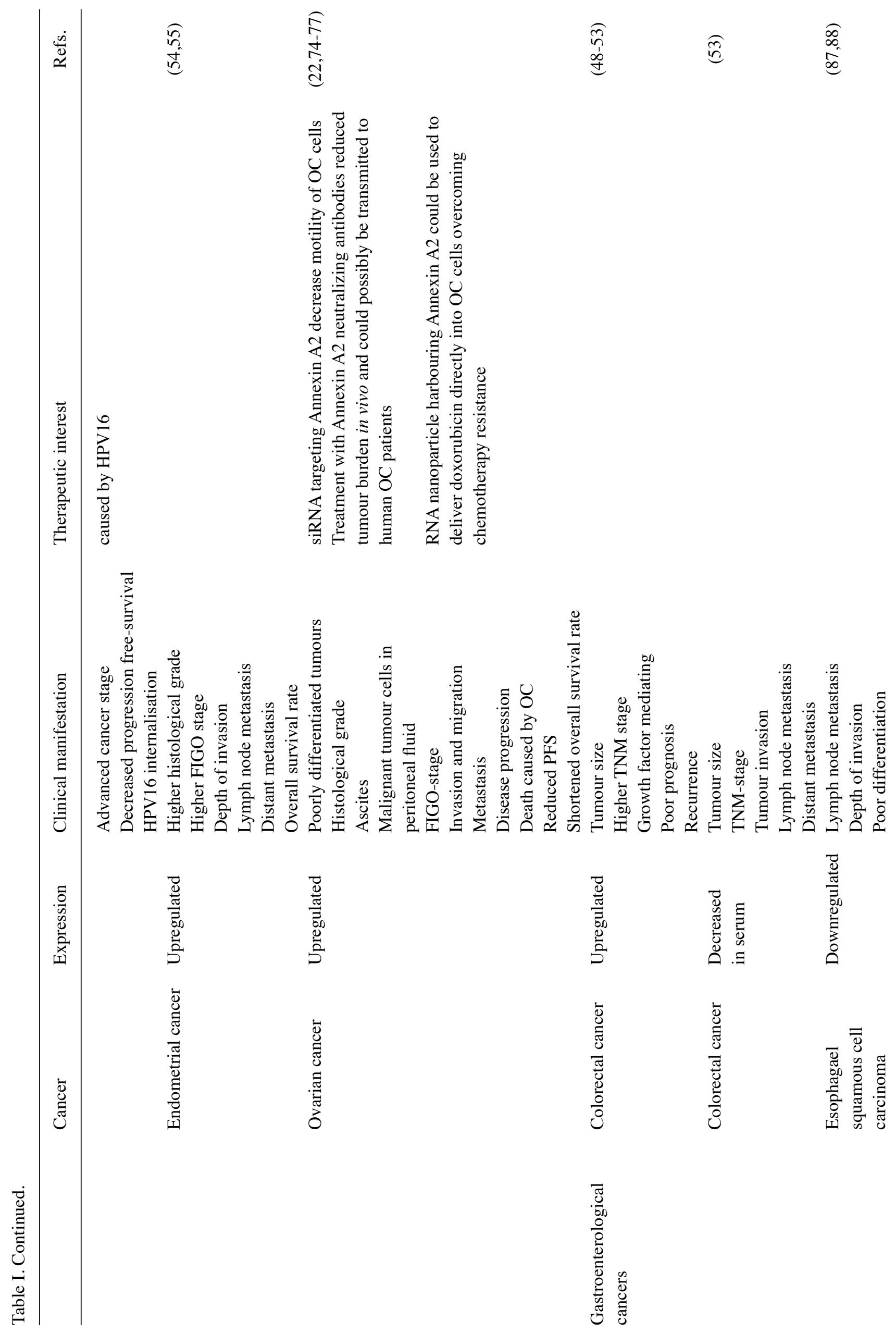




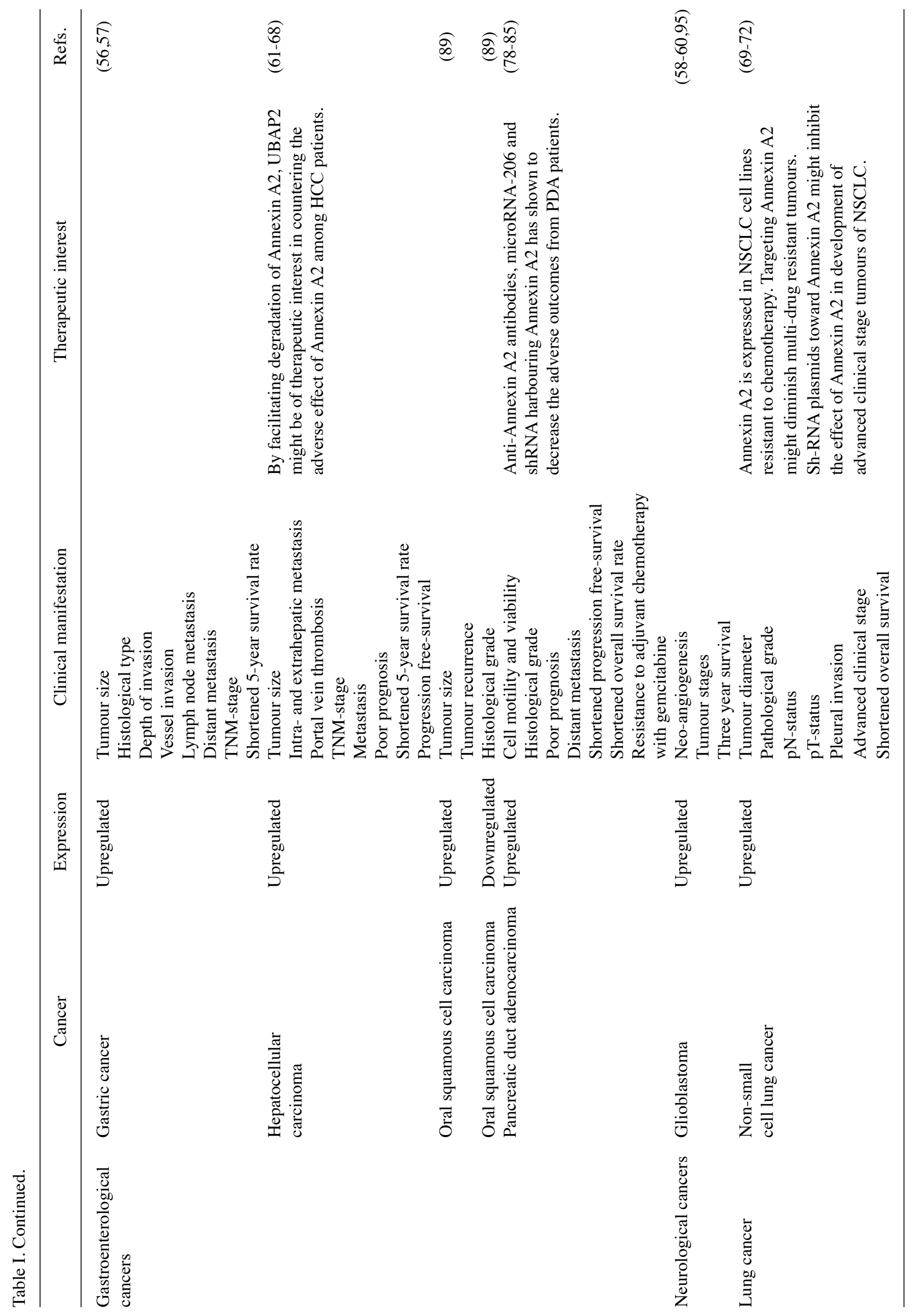


late the production of plasmin combined with the functional role of plasmin, indicates the possible role of Annexin A2 in angiogenesis and metastasis of breast cancer cells $(43,94)$. Annexin A2 has been shown to maintain constitutive activation of the EGFR-pathway leading to cell proliferation, migration and viability (94). Annexin A2 downregulation by siRNA increased apoptosis and decreased cell viability and migration by inhibiting the Annexin A2 induced, constitutively active EGFR-pathway (44). Furthermore, it was shown that antiAnnexin A2 antibodies inhibited neo-angiogenesis by inducing apoptotic cell death of endothelial cells (94). This suggests that siRNA against Annexin A2 could be of therapeutic value in HER-2 negative, herceptin-resistant cancer cells.

\section{Gynaecological cancers}

Cervical cancer. Abnormal expression of Annexin A2 and S100A proteins has been reported to induce resistance to cisplatin-based chemotherapy among cervical cancer patients. IHC analysis showed increased Annexin A2 expression in cervical tumour stromal cells after chemotherapy treatment. In addition to this, Annexin A2 tumour expression was significantly higher in the group of tumours not responding to chemotherapy treatment, indicating that Annexin A2 upregulation may play a role in resistance to chemotherapy. Furthermore, Annexin A2 expression in stromal cells of cervical cancer patient is an independent prognostic factor for decreased progression free-survival $(46,47)$. Annexin A2 was shown to be positively correlated with advanced cancer (47) indicating how expression of Annexin A2 relates to higher cancer stages.

Human papilloviruses (HPV) are sexually transmitted viruses that causally associate with the development of cervical cancers. The most common, HPV16, is an obligatory intracellular virus that must gain entry into host cells to survive (48). This HPV16 internalisation has been demonstrated to be partly facilitated by the Annexin A2-S100A10 heterotetramer. By inhibiting Annexin A2 in an endogenous manner or with anti-Annexin A2 antibodies, the HPV16 internalisation was significantly decreased.

Endometrial cancer. Annexin A2 is expressed in both membrane and the cytoplasm of endometrial cancer cells in $95.2 \%$ of the endometrial carcinomas compared to $55.6 \%$ of the normal endometrium $(\mathrm{P}<0.05)(55)$. In vitro studies suggest Annexin A2 may play a role in the promotion of metastasis in that endometrial cancer. Knockdown of Annexin A2 resulted in the absence of lung and hematogenous metastasis (56), implying Annexin A2 to play a role in the development of distant metastasis among patients with endometrial cancer. For $91.7 \%$ (22/24) of endometrial carcinoma patients in stage III-IV, a high expression of Annexin A2 was found. The expression was significantly higher than for patients in stage I-II with $55 \%$ $(33 / 60)(\mathrm{P}<0.05)$. Overexpression of Annexin A2 is correlated with shorter overall survival $(\mathrm{P}<0.05)$ (55). Together, this suggests that Annexin A2 could be a potential therapeutic focus in order to avoid spread of endometrial tumours and to predict recurrence and overall survival.

Ovarian cancer $(O C)$. Annexin A2 is expressed in the membrane $(77 \%)$ and the cytoplasm $(82.6 \%)$ of serous OC cells as well as the surrounding stromal cells (58.5\%) (75).
Annexin A2 seems to play a role in regulating cell proliferation of OC cell lines (76). A significant increase in Annexin A2 expression in FIGO-stage IV compared to stage II and III is reported $(\mathrm{P}=0.001$ and $\mathrm{P}=0.005$, respectively) (75). Annexin $\mathrm{A} 2$ expression is related to histological grade $(\mathrm{P}=0.002)(76)$. Furthermore, high expression of Annexin A2 was significantly related to presence of ascites $(\mathrm{P}<0.001)$ and malignant tumour cells in peritoneal fluid $(\mathrm{P}<0.001)(76)$. Downregulation of Annexin A2 in OC cells significantly reduced the ability of invasion and migration $(\mathrm{P}<0.05)$. By analysing metastasis from OC patients it was revealed that there was a high number of lung metastatic nodules in the high Annexin A2 expression group, whereas almost no lung metastasis were found in the low expression group (25). High stromal expression is significantly associated with reduced progression-free survival (PFS) $(\mathrm{P}=0.014)$ and reduced overall survival (OS) (75). Patients with high stromal Annexin A2 had a 1.8-fold increased risk of disease progression $(\mathrm{P}=0.0014)$ and a 1.6 -fold increased risk of disease related death $(\mathrm{P}=0.046)$ (75). Combined with S100A10, Annexin A2 expression predicts adverse outcomes for OC patients. For patients with high expression of stromal Annexin A2 and cytoplasmic S100A10 the 5-year survival rate was $11.1 \%$ compared to $50 \%$ for the patients with low stromal Annexin A2 and cytoplasmic S100A10 (75).

siRNA targeting Annexin A2 significantly decreased motility $(\mathrm{P}=0.0069)$ and invasion $(\mathrm{P}=0.0047)$ in $\mathrm{OC}$ cell lines. In vivo studies in mice showed how treatment with Annexin A2 neutralizing antibodies significantly reduced the tumour burden (77). This makes siRNA targeting Annexin A2 and Annexin A2 neutralizing antibodies a potential therapeutic focus of $\mathrm{OC}$ treatment. Another study showed that RNA-nanoparticles harbouring Annexin A2 can be used to deliver doxorubicin into the OC cells. Knowledge of this mechanism may help overcome chemotherapy resistant OC and to minimize the adverse effect of chemotherapy to healthy tissue (78).

\section{Gastroenterological cancers}

Colorectal cancer (CRC). Annexin A2 is highly expressed in CRC cell lines, both on mRNA level and as protein (49). The expression of Annexin A2 is shown to induce significant changes on the microstructure of the cells (50). Upregulated Annexin A2 promotes proliferation, migration and invasion of CRC cells in vitro caused by the changes in microstructure (49). In studies investigating Annexin A2 using IHC, high expression of Annexin A2 was significantly correlated with tumour size $(\mathrm{P}=0.03)$, poorly differentiated tumours $(\mathrm{P}=0.01)$, depth of invasion $(\mathrm{P}=0.02)$ and TNM-stage $(\mathrm{P}=0.02)(51)$. Annexin A2 was shown to be an independent factor for poor prognosis in patients with CRC (51). Annexin A2 in the cell membrane is a characteristic for tumours with high invasiveness. This ability to invade tissue shows how Annexin A2 could affect lymph node metastasis $(52,53)$. Annexin A2 has also been shown to be important for the effect of progastrins and gastrins, hereby partially mediating the effect of growth factors on colon cancer cells (95). Furthermore, Annexin A2 could be used to predict recurrence of CRC. The 5-year recurrence rate was $69.4 \%$ in the high expression group compared to $35.9 \%$ in the low expression group among patients with stage I-II disease (53). On the other hand, the serum Annexin A2 level is significantly 
lower in patients with CRC compared with healthy controls $(\mathrm{P}<0.001)$ (54). Low serum Annexin A2 levels were related to increased tumour size $(\mathrm{P}=0.003)$, higher TNM-stage $(\mathrm{P}=0.004)$, tumour invasion $(\mathrm{P}=0.005)$, lymph node metastasis $(\mathrm{P}=0.003)$ and distant metastasis $(\mathrm{P}=0.005)(54)$. This makes Annexin A2 levels in serum of interest to classify colon cancer patients.

Oesophageal squamous cell carcinoma (ESCC) and oral squamous cell carcinoma (OSCC). Annexin A2 is downregulated on both mRNA and protein level in ESCC cells $(88,89)$. Annexin A2 was found in 9.1\% (2/22) of the ESCC samples compared to $90.9 \%(20 / 22)$ of the controls using qRT-PCR and western blot analysis. The expression of Annexin A2 was confirmed by IHC. Annexin A2 in ESCC cells is found mainly in the cell membrane. Low Annexin A2 expression is correlated with lymph node metastasis $(\mathrm{P}<0.05)$, depth of invasion $(\mathrm{P}<0.05)$ and poor differentiation $(\mathrm{P}<0.05)(88)$.

Annexin A2 is expressed in the cell membrane of normal epithelial cells of the oral cavity. Annexin A2 was expressed in $82 \%(87 / 106)$ of the OSCC cases (90). Annexin A2 is associated with histological grade $(\mathrm{P}=0.02)$. Low expression of Annexin A2 is seen in poorly differentiated tumours compared to well differentiated tumours (90). On the contrary, a higher expression of Annexin A2 correlated to tumour size $(\mathrm{P}=0.003)$ and tumour recurrence $(\mathrm{P}=0.04)(90)$.

There are few studies investigating the expression of Annexin A2 and its relation to ESCC and OSCC. The studies reviewed have at low number of participants, 22 and 106, respectively, and it is therefore difficult to indicate a clear correlation between the expression of Annexin A2 and ESCC and OSCC.

Gastric cancer. Annexin A2 is found predominantly on the cell membrane of gastric cancer cells. Annexin A2 is found in non-tumour mucosa and in human gastric cancer cases in 19.6 and $40.1 \%$ of patients, respectively $(57,58)$. The expression of Annexin A2 correlates with tumour size (57), histological type (57), depth of invasion (57), vessel invasion (57), lymph node metastasis, distant metastasis and TNM-stage $(\mathrm{P}<0.05)$ (57,58). Furthermore, for cancer stages I, II and III, the 5-year survival rate of the patients with high expression of Annexin A2 were significantly lower compared with 5-year survival for the patients with low expression (57).

Hepatocellular carcinoma (HCC). Annexin A2 expression is localized to the cell membrane and cytoplasm of HCC cells $(62,63)$. Annexin A2 expression was found in $73.8 \%$ $(62 / 84)$ of the HCC tissues compared to $35.6 \%$ (21/59) of the benign liver disease $(\mathrm{BLD})$ tissue $(\mathrm{P}<0.001)(64)$. Tumours with a high expression of Annexin A2 were larger in size compared to low expression tumours $(\mathrm{P}=0.016)(63,65)$. Annexin A2 expression significantly correlated with intrahepatic metastasis $(\mathrm{P}=0.02)$, portal vein thrombosis $(\mathrm{P}=0.003)$ and higher TNM-stage $(\mathrm{P}=0.024)(64,66)$. Survival analysis revealed how the high expression group had a poorer prognosis and a shortened 5-year survival rate $(63,64)$. Furthermore, Annexin A2 seems to regulate actin remodelling thereby facilitating invasion and metastasis of HCC cells making high expression of Annexin A2 a marker for metastatic potential of
HCC cells $(67,68)$. By comparing serum levels of Annexin A2 from $\mathrm{HCC}$ patients and BLD patients, it was revealed that Annexin A2 was significantly elevated even at early stage HCC ( $\mathrm{P}=0.0024$ and $\mathrm{P}=0.0048$, respectively) (69). Monitoring Annexin A2 expression levels in combination with alfa fetoprotein may contribute to a higher sensitivity and specificity in the clinical practice of diagnosing HCC (69). Ubiquitin associated protein 2 (UBAP2) has been shown to make a complex with Annexin A2, marking it for degradation. This makes UBAP2 a potential therapeutic focus for patients with $\mathrm{HCC}$ to counter the adverse effects of Annexin A2 (63).

Pancreatic duct adenocarcinoma (PDA). Annexin A2 is localized in the cytoplasm of normal pancreatic epithelial cells. In late stage pancreatic intraepithelial neoplasia (PanIN) and invasive PDA, Annexin A2 is relocated to the outer luminal surface (79). The expression of Annexin A2 gives PDA tumour cells the ability to grow into the liver (79). Annexin A2 has been shown to co-localize with S100A6 on the cell membrane of PDA tumours. Annexin A2 combined with S100A6 contributes to PDA cell motility (81). Annexin A2 is also significantly associated with histopathological grading $(\mathrm{P}=0.029)$ (82). Annexin A2 promotes secretion of the class 3 Semaphorin Sema3D. It was demonstrated how Sema3D is enriched in metastatic tumours of PDA. Furthermore, Sema3D is expressed in primary PDA from patients with a poor prognosis and patients who died from widely metastatic disease (79). This indicates how Annexin A2, through Sema3D, promotes metastasis in human PDA and could predict a poor prognosis for PDA patients (79). Another mechanism by which Annexin A2 promotes invasion of PDA cells is mediated by Tyrosine 23 phosphorylation of Annexin A2 (80). Annexin A2 can interact with the p50 subunit of $N F-\kappa B$ independently of calcium. By interfering with NF- $\kappa$ B Annexin A2 helps to induce cellular viability of PDA (83). An in vivo study on mice showed how expression of Annexin A2 significantly correlated with a shortened survival rate $(\mathrm{P}=0.001)(80)$. Attributing to this, patients with high expression of Annexin A2 showed a significantly shortened PFS and OS compared to low expression patients ( $\mathrm{P}=0.008$ and $\mathrm{P}=0.033$, respectively) (84). Treatment with anti-Annexin A2 antibodies prolonged the survival rate of mice compared with mice treated with isotype control IgG $(\mathrm{P}=0.02)$. Furthermore, microRNA-206 has shown the ability to reduce Annexin A2 plasmin production and thereby inhibiting PDA cell invasion (86).

Takano et al (84) examined the relevance of Annexin A2 in drug-resistant PDA and found high expression of Annexin A2 as an independent factor for recurrence in patients undergoing gemcitabine adjuvant chemotherapy. Knocking down Annexin A2 by shRNA significantly increased the cytotoxic effect of gemcitabine by the following downregulation of the $\mathrm{NF}-\kappa \mathrm{B}$ pathway (83).

These studies of anti-Annexin A2 antibodies, microRNA-206 and shRNA targeting Annexin A2 altogether indicate Annexin A2 to be of therapeutic relevance in patients with PDA (85).

\section{Neurological cancers}

Glioblastoma. The majority of human glioblastoma cases expressed Annexin A2 (59,60). Twenty-five out of 30 cases 
Table II. Summary of the clinical manifestations of overexpression of Annexin A2 and the organ related cancer site.

\begin{tabular}{|c|c|}
\hline Clinical manifestation & Organ related cancer site \\
\hline Resistance to treatment & $\begin{array}{l}\text { Acute lymphoblastic leukaemia, breast, cervical, pancreatic duct adenocarcinoma, } \\
\text { prostate cancer }\end{array}$ \\
\hline Binding to the bone marrow & Acute lymphoblastic leukaemia, multiple myeloma, prostate cancer \\
\hline pT-stage & $\begin{array}{l}\text { Clear cell renal cell carcinoma, colorectal, esophageal squamous cell } \\
\text { carcinoma (downregulation), endometrial, gastric, hepatocellular carcinoma, } \\
\text { non-small cell lung, ovarian, oral squamous cell carcinoma, urothelial cancer }\end{array}$ \\
\hline pN-stage & $\begin{array}{l}\text { Clear cell renal cell carcinoma, colorectal, esophageal squamous cell carcinoma } \\
\text { (downregulation), endometrial, gastric, non-small cell lung cancer, ovarian, pancreatic duct } \\
\text { adenocarcinoma, prostate (downregulation), urothelial cancer }\end{array}$ \\
\hline pM-stage & $\begin{array}{l}\text { Clear cell renal cell carcinoma, breast, colorectal, endometrial, gastric, hepatocellular } \\
\text { carcinoma, ovarian, pancreatic duct adenocarcinoma, prostate (downregulation), } \\
\text { urothelial cancer }\end{array}$ \\
\hline Histological grade and type & $\begin{array}{l}\text { Clear cell renal cell carcinoma, cervical, endometrial, gastric, non-small cell lung, ovarian, } \\
\text { oral squamous cell carcinoma (downregulation), pancreatic duct adenocarcinoma, } \\
\text { prostate cancer }\end{array}$ \\
\hline Shortened survival & $\begin{array}{l}\text { Clear cell renal cell carcinoma, endometrial, gastric, glioblastoma, hepatocellular carcinoma, } \\
\text { non-small cell lung, ovarian, pancreatic duct adenocarcinoma, prostate cancer (downregulation) }\end{array}$ \\
\hline
\end{tabular}

were Annexin A2 positive, with 11/30 cases strongly positive, $14 / 30$ cases weakly positive and the remaining 5 cases negative (60). Annexin A2 expression is not detectable in normal glia cells (96). Furthermore, Annexin A2 is overexpressed in the cases with a higher grade tumour, pathological grade II-IV, compared to low grade tumours without infiltration (61). The 3-year OS rate of the Annexin A2 positive group was significantly lower than survival of the Annexin A2 negative group, 31.5 and $51.8 \%$, respectively (59). Annexin A2 expression was shown to correlate with vascular endothelial growth factor (VEGF) and platelet-derived growth factor (PDGF), $\mathrm{P}<0.05$. Annexin A2's effect on glioblastoma cells through VEGF and PDGF may represent an important anti-angiogenesis therapeutic target in the treatment of glioma (60). A significant lower cell proliferation was shown after knockdown of Annexin A2 by using a wound closure rate (59). Knockdown of Annexin A2 reduced the invasiveness of glioma cells (59).

\section{Lung cancer}

Non-small cell lung cancer (NSCLC). Annexin A2 is shown in cytoplasm and cell membranes in lung adenocarcinoma cells lines (70). Annexin A2 expression is significantly correlated with tumour diameter $(\mathrm{P}=0.003)$, pathological grade $(\mathrm{P}=0.014)$, pT status $(\mathrm{P}<0.001)$ and pleural invasion $(71)$. High expression of Annexin A2 was associated with lymph node metastasis in comparison with tumours with low Annexin A2 expression $(\mathrm{P}<0.001)(72)$. Annexin A2 overexpression correlates to advanced clinical stage $(\mathrm{P}<0.001)$ and patients with high Annexin A2 expression have shorter survival compared to patients with low expression $(\mathrm{P}<0.001)(71,72)$.

Short hairpin plasmid mediated RNA (shRNA) interference is a way of post-translation gene silencing (70). A plasmid expressing a shRNA targeting Annexin A2 could effectively inhibit the expression of Annexin A2. This implies that the shRNA plasmid against Annexin A2 could be of therapeutic interest to decrease the proliferation and invasion capability of NSCLC cells (70).

Another study using immunoprecipitation and flow cytometry showed Annexin A2 expression and phosphorylation in cell lines with resistance properties to doxorubicin, vinca alkaloids and epipodophyllotoxins indicating a relation of Annexin A2 to prediction of multi-drug resistance (73).

\section{Discussion}

The mechanism for Annexin A2 influence in different tumour types varies and thus the general role of Annexin A2 in malignant tumours remains unclear. Table II summarizes the clinical manifestations correlated to overexpression of Annexin A2 and the cancers in which they are represent. In general it seems that upregulation is the predominant phenomenon which can be correlated to an adverse clinical outcome for the patients.

Annexin collaborate with different proteins such as plasminogen, S100A10 and HE4. It might be the complex interaction between these agents and Annexin A2 that play a part in its malignant potential. Activation by phosphorylation seems to play a role in carcinogenesis and to some extent Annexin A2 seems to be regulated by Annexin A5. This accentuates the need to investigate the expression patterns of different Annexins within the different cancer forms. The ongoing regulation and collaboration of Annexin A2 might be the foundation for its malignant potential and might be the focus for further investigation on targeting treatment toward Annexins and plasminogen, S100 proteins and HE4.

Although it is hypothesised how Annexin A2 mediated activation of proteases leads to tumour cell proliferation and invasion, the fact that Annexin A2 is downregulated in some malignant tumours, poses some inconsistencies in the theory of Annexin A2 relation in carcinogenesis. 
By making this overview on Annexin A2 expression in different cancers there were some contradicting studies on the topic $(90-92,97)$. For OSCC and prostate cancer, a downregulation of Annexin A2 was demonstrated. Differences between demographic data (age, sex and time of data collection) could influence the outcome of the results in both studies investigating OSCC and prostate cancer. The influence is more noticeable when the number of patients is low, and larger studies to confirm results are needed. In the OSCC study by Rodrigo Tapia et al (90) the non-malignant tissue from patients undergoing non-cancerous surgery was investigated. In another study by Zhong et al (97) the nonmalignant tissue is not taken from healthy controls but taken from the cancer patients as biopsies of epithelial tissue $2 \mathrm{~cm}$ from the cancer. This difference could be debated because it is not well known which kind of non-malignant tissue is best standard for comparison.

Yee et al (91) suggests that Annexin A2 expression distinguish benign illnesses of the prostate gland, like basal cell hyperplasia and prostate atrophy, from high grade intraepithelial neoplasia and prostate cancer. Conflicting data on the Annexin A2 expression in tumours with Gleason score 8-10 has been published. Ding et al (92) did not confirm upregulation of Annexin A2 in Gleason score 8-10 tumours. The contradictive data could be caused by a different scoring of expression levels in combination with the slightly different laboratory protocol. Although both studies used the same Annexin A2 mouse antibody different kit lot number may result in staining differences.

The dichotomic expression of Annexin A2 in different cancers emphasizes the need to characterize the individual protein expression profiles according to the different cancers. That said, it might not be of interest to make a comparison of Annexin A2 expression among different cancers but more relevant to have a broader knowledge of Annexin A2 profiling within the different cancer subtypes.

All the studies enrolled in the present review were using IHC which gives them some limitations. The staining level, antibody concentration and cut-off values could be different among studies. When comparing the staining level of Annexin A2 the individual pathologist makes the classification of the tumours. No international scoring system for Annexin A2 exists. In most of the studies in this review, two independent pathologists made the scoring resulting in a consensus score. If Annexin A2 should be used in clinical routine setting then the quality of staining should be monitored by attending an assurance program.

This review has some limitations. Even though we sought to run through the literature of Annexin A2 and cancer, not all human tumour types are included. Secondly, within the cancer forms it is not discussed on behalf of the individual histological cancers subtypes. All histological subtypes are included and might therefore give a less specific correlation. Thirdly, publications bias cannot be completely ruled out because of the tendency to include papers with positive results compared to negative results. This bias is elaborated by discussing the papers giving a negative result.

Looking at the possibility of implementing IHC staining for Annexin A2 in the common practice at the hospital, the actual use of IHC and the possibility of elaborating the IHC panel are evaluated. IHC is a supplement to the histopathological description. Today most tumours are already undergoing IHC staining with other antibodies. Having to stain for Annexin A2 would only be an extension to the IHC panel that are used today.

Overall there is a limited amount of research on the topics concerning the Annexin A2 expression and recurrence rates of different cancers or the possible correlation between upregulated Annexin A2 and primary chemoresistance. Also there is a need for more profound research on the pathways and mechanisms of Annexin A2 in tumour genesis. This should be of interest because of the potential of Annexin A2 as a therapeutic agent in the treatment of different cancers. There are only a limited number of studies concerning the use of anti-Annexin A2 antibodies on human cancers tissue but the results on mice are promising (98). The ability of siRNAs to interfere with Annexin A2 expression might be of interest in the treatment of malignant diseases because of its potential to diminish treatment resistance and hyperfibrinolytic complications $(39,44)$. There is a growing need to individualize cancer treatment and it could be of interest to have more knowledge on the use on anti-Annexin A2 antibodies and siRNAs on human cancer cells.

\section{Conclusion}

Overall, the present study reviews the ability of Annexin A2 expression in various cancer cells to predict adverse outcome. Expression of Annexin A2 is correlated to advanced stages and metastatic disease. Annexin A2 is demonstrated to predict reduced OS, shortened PFS and resistance to present treatment regimens. Although an overexpression of Annexin A2 is correlated to adverse outcome of the patient, a lowered expression of Annexin A2 is also correlated to poor prognosis in a few cancer types.

The present review sought to make an outline on Annexin A2s influence on cancer and make a basis for further investigation hereby contributing to knowledge of Annexin A2 resulting in consensus of a possible clinical use of this biomarker.

\section{Acknowledgements}

A special thanks to Julie Lilith Hentze at the Department of Pathology, Molecular Unit, Herlev Hospital, University of Copenhagen for guidance and discussions during manuscript processing. The Danish Cancer Society kindly funded a scholarship for the first author (M.V.C.) as part of a Research Year Project (grant no. R165-A10261-16-S7).

\section{References}

1. Gerke V and Moss SE: Annexins: From structure to function. Physiol Rev 82: 331-371, 2002.

2. Deora AB, Kreitzer G, Jacovina AT and Hajjar KA: An annexin 2 phosphorylation switch mediates p11-dependent translocation of annexin 2 to the cell surface. J Biol Chem 279: 43411-43418, 2004.

3. Wang CY and Lin CF: Annexin A2: Its molecular regulation and cellular expression in cancer development. Dis Markers 2014, 308976, 2014. doi: 10.1155/2014/308976.

4. Filipenko NR and Waisman DM: The $\mathrm{C}$ terminus of annexin II mediates binding to F-actin. J Biol Chem 276: 5310-5315, 2001. 
5. Kassam G, Manro A, Braat CE, Louie P, Fitzpatrick SL and Waisman DM: Characterization of the heparin binding properties of annexin II tetramer. J Biol Chem 272: 15093-15100, 1997.

6. Hajjar KA, Jacovina AT and Chacko J: An endothelial cell receptor for plasminogen/tissue plasminogen activator. I. Identity with annexin II. J Biol Chem 269: 21191-21197, 1994.

7. Sarafian T, Pradel LA, Henry JP, Aunis D and Bader MF: The participation of annexin II (calpactin I) in calcium-evoked exocytosis requires protein kinase C. J Cell Biol 114: 1135-1147, 1991.

8. Emans N, Gorvel JP, Walter C, Gerke V, Kellner R, Griffiths G and Gruenberg J: Annexin II is a major component of fusogenic endosomal vesicles. J Cell Biol 120: 1357-1369, 1993.

9. Babiychuk EB and Draeger A: Annexins in cell membrane dynamics. $\mathrm{Ca}^{2+}$-regulated association of lipid microdomains. J Cell Biol 150: 1113-1124, 2000.

10. Chiang Y, Rizzino A, Sibenaller ZA, Wold MS and Vishwanatha JK: Specific down-regulation of annexin II expression in human cells interferes with cell proliferation. Mol Cell Biochem 199: 139-147, 1999.

11. Oliferenko S, Paiha K, Harder T, Gerke V, Schwärzler C, Schwarz H, Beug H, Günthert U and Huber LA: Analysis of CD44-containing lipid rafts: Recruitment of annexin II and stabilization by the actin cytoskeleton. J Cell Biol 146: 843-854, 1999.

12. Huang Y, Yan $\mathrm{CH}$ and Fu SB: The cloning and expression of apoptosis associated gene ANNEXIN A2 induced by p53 gene. Zhonghua Yi Xue Yi Chuan Xue Za Zhi 22: 661-664, 2005 (In Chinese).

13. Waters KM, Stenoien DL, Sowa MB, von Neubeck C, Chrisler WB, Tan R, Sontag RL and Weber TJ: Annexin A2 modulates radiation-sensitive transcriptional programming and cell fate. Radiat Res 179: 53-61, 2013.

14. Coméra C, Rothhut B and Russo-Marie F: Identification and characterization of phospholipase A2 inhibitory proteins in human mononuclear cells. Eur J Biochem 188: 139-146, 1990.

15. Fan X, Krahling S, Smith D, Williamson P and Schlegel RA Macrophage surface expression of annexins I and II in the phagocytosis of apoptotic lymphocytes. Mol Biol Cell 15: 2863-2872, 2004.

16. Choi KS, Fitzpatrick SL, Filipenko NR, Fogg DK, Kassam G, Magliocco AM and Waisman DM: Regulation of plasmindependent fibrin clot lysis by annexin II heterotetramer. J Biol Chem 276: 25212-25221, 2001.

17. Ling Q, Jacovina AT, Deora A, Febbraio M, Simantov R, Silverstein RL, Hempstead B, Mark WH and Hajjar KA: Annexin II regulates fibrin homeostasis and neoangiogenesis in vivo. J Clin Invest 113: 38-48, 2004.

18. Chen H, Xu C, Jin Q and Liu Z: S100 protein family in human cancer. Am J Cancer Res 4: 89-115, 2014.

19. Liu Y, Myrvang HK and Dekker LV: Annexin A2 complexes with S100 proteins: Structure, function and pharmacological manipulation. Br J Pharmacol 172: 1664-1676, 2015.

20. Monastyrskaya K, Babiychuk EB, Hostettler A, Rescher U and Draeger A: Annexins as intracellular calcium sensors. Cell Calcium 41: 207-219, 2007

21. Myrvang HK, Guo X, Li C and Dekker LV: Protein interactions between surface annexin A2 and S100A10 mediate adhesion of breast cancer cells to microvascular endothelial cells. FEBS Let 587: 3210-3215, 2013

22. Sharma MC and Sharma M: The role of annexin II in angiogenesis and tumor progression: A potential therapeutic target. Curr Pharm Des 13: 3568-3575, 2007.

23. Bolon I, Zhou HM, Charron Y, Wohlwend A and Vassalli JD: Plasminogen mediates the pathological effects of urokinase-type plasminogen activator overexpression. Am J Pathol 164: 2299. $2304,2004$.

24. Madureira PA, Bharadwaj AG, Bydoun M, Garant K, O'Connell P, Lee $\mathrm{P}$ and Waisman DM: Cell surface protease activation during RAS transformation: Critical role of the plasminogen receptor, S100A10. Oncotarget 7: 47720-47737, 2016.

25. Zhuang H, Tan M, Liu J, Hu Z, Liu D, Gao J, Zhu L and Lin B: Human epididymis protein 4 in association with Annexin II promotes invasion and metastasis of ovarian cancer cells. Mol Cancer 13: 243, 2014

26. Yang $M$ and Huang $C Z$ : Mitogen-activated protein kinase signaling pathway and invasion and metastasis of gastric cancer. World J Gastroenterol 21: 11673-11679, 2015.

27. Sulzmaier FJ, Jean C and Schlaepfer DD: FAK in cancer: Mechanistic findings and clinical applications. Nat Rev Cancer 14: 598-610, 2014
28. O'Reilly MS, Holmgren L, Shing Y, Chen C, Rosenthal RA, Moses M, Lane WS, Cao Y, Sage EH and Folkman J: Angiostatin: A novel angiogenesis inhibitor that mediates the suppression of metastases by a Lewis lung carcinoma. Cell 79: 315-328, 1994.

29. Wahl ML, Kenan DJ, Gonzalez-Gronow M and Pizzo SV: Angiostatin's molecular mechanism: Aspects of specificity and regulation elucidated. J Cell Biochem 96: 242-261, 2005.

30. Mai J, Waisman DM and Sloane BF: Cell surface complex of cathepsin $\mathrm{B} / \mathrm{annexin}$ II tetramer in malignant progression. Biochim Biophys Acta 1477: 215-230, 2000.

31. Mai J, Finley RL Jr, Waisman DM and Sloane BF: Human procathepsin B interacts with the annexin II tetramer on the surface of tumor cells. J Biol Chem 275: 12806-12812, 2000.

32. Roodman GD: Genes associate with abnormal bone cell activity in bone metastasis. Cancer Metastasis Rev 31: 569-578, 2012

33. Jung Y, Shiozawa Y, Wang J, Patel LR, Havens AM, Song J, Krebsbach PH, Roodman GD and Taichman RS: Annexin-2 is a regulator of stromal cell-derived factor-1/CXCL12 function in the hematopoietic stem cell endosteal niche. Exp Hematol 39: 151-166.e1, 2011.

34. Jung Y, Wang J, Lee E, McGee S, Berry JE, Yumoto K, Dai J, Keller ET, Shiozawa Y and Taichman RS: Annexin 2-CXCL12 interactions regulate metastatic cell targeting and growth in the bone marrow. Mol Cancer Res 13: 197-207, 2015.

35. D'Souza S, Kurihara N, Shiozawa Y, Joseph J, Taichman R, Galson DL and Roodman GD: Annexin II interactions with the annexin II receptor enhance multiple myeloma cell adhesion and growth in the bone marrow microenvironment. Blood 119: 1888-1896, 2012.

36. Spijkers-Hagelstein JA, Mimoso Pinhanços S, Schneider P, Pieters R and Stam RW: Src kinase-induced phosphorylation of annexin A2 mediates glucocorticoid resistance in MLL-rearranged infant acute lymphoblastic leukemia. Leukemia 27: 1063-1071, 2013.

37. Gopalakrishnapillai A, Kolb EA, Dhanan P, Mason RW, Napper A and Barwe SP: Disruption of Annexin II/p11 interaction suppresses leukemia cell Binding, homing and engraftment, and sensitizes the leukemia cells to chemotherapy. PLoS One 10: e0140564, 2015.

38. Menell JS, Cesarman GM, Jacovina AT, McLaughlin MA, Lev EA, Hajjar KA: Annexin II and bleeding in acute promyelocytic leukemia. N Engl J Med 340, 994-1004, 1999.

39. Liu Y, Wang Z, Jiang M, Dai L, Zhang W, Wu D and Ruan C: The expression of annexin II and its role in the fibrinolytic activity in acute promyelocytic leukemia. Leuk Res 5: 879-84, 2011

40. Olwill SA, McGlynn H, Gilmore WS and Alexander HD All-trans retinoic acid-induced downregulation of annexin II expression in myeloid leukaemia cell lines is not confined to acute promyelocytic leukaemia. Br J Haematol 131: 258-264, 2005.

41. Yang J, Cheng TT, Wang LN, Chen W and Li X: The expression and clinical significance of Annexin II in clear-cell renal cell carcinoma. Xi Bao Yu Fen Zi Mian Yi Xue Za Zhi 28: 59-62, 2012 (In Chinese).

42. Ohno Y, Izumi M, Kawamura T, Nishimura T, Mukai K and Tachibana M: Annexin II represents metastatic potential in clearcell renal cell carcinoma. Br J Cancer 101: 287-294, 2009

43. Sharma MR, Koltowski L, Ownbey RT, Tuszynski GP and Sharma MC: Angiogenesis-associated protein annexin II in breast cancer: Selective expression in invasive breast cancer and contribution to tumor invasion and progression. Exp Mol Pathol 81: $146-156,2006$

44. Shetty PK, Thamake SI, Biswas S, Johansson SL and Vishwanatha JK: Reciprocal regulation of annexin A2 and EGFR with Her-2 in Her-2 negative and herceptin-resistant breast cancer. PLoS One 7: 44299, 2012.

45. Sharma M, Blackman MR and Sharma MC: Antibody directed neutralization of annexin II (ANX II) inhibits neoangiogenesis and human breast tumor growth in a xenograft model. Exp Mol Pathol 92: 175-184, 2012.

46. Jin L, Shen Q, Ding S, Jiang W, Jiang L and Zhu X: Immunohistochemical expression of Annexin A2 and S100A proteins in patients with bulky stage IB-IIA cervical cancer treated with neoadjuvant chemotherapy. Gynecol Oncol 126: 140-146, 2012.

47. Choi CH, Chung JY, Chung EJ, Sears JD, Lee JW, Bae DS and Hewitt SM: Prognostic significance of annexin A2 and annexin A4 expression in patients with cervical cancer. BMC Cancer 16: 448 , 2016.

48. Woodham AW, Da Silva DM, Skeate JG, Raff AB, Ambroso MR, Brand HE, Isas JM, Langen R and Kast WM: The S100A10 subunit of the annexin A2 heterotetramer facilitates L2-mediated human papillomavirus infection. PLoS One 7: e43519, 2012. 
49. Xiu D, Liu L, Qiao F, Yang H, Cui L and Liu G: Annexin A2 coordinates STAT3 to regulate the invasion and migration of colorectal cancer cells in vitro. Gastroenterol Res Pract 2016, 3521453, 2016. doi:https://doi.org/10.1155/2016/3521453.

50. Xing R, He H, He Y, Feng Y, Zhang C, Wu H, Sun M, Yu X, Liu Y, Song X, et al: ANXA2 remodels the microstructures of caco2 cells. Cell Mol Biol 59: (59 Suppl): OL1848-54, 2013.

51. Emoto K, Yamada Y, Sawada H, Fujimoto H, Ueno M, Takayama T, Kamada K, Naito A, Hirao S and Nakajima Y: Annexin II overexpression correlates with stromal tenascin-C overexpression: A prognostic marker in colorectal carcinoma Cancer 92: 1419-1426, 2001.

52. Tristante E, Martínez CM, Jiménez S, Mora L, Carballo F, Martínez-Lacaci I and de Torre-Minguela C: Association of a characteristic membrane pattern of annexin A2 with high invasiveness and nodal status in colon adenocarcinoma. Transl Res 166: 196-206, 2015.

53. Yang T, Peng H, Wang J, Yang J, Nice EC, Xie K and Huang C: Prognostic and diagnostic significance of annexin A2 in colorectal cancer. Colorectal Dis 15: e373-e381, 2013.

54 Gurluler E, Guner OS, Tumay LV, Turkel Kucukmetin N, Hizli B and Zorluoglu A: Serum annexin A2 levels in patients with colon cancer in comparison to healthy controls and in relation to tumor pathology. Med Sci Monit 20: 1801-1807, 2014

55. Deng L, Gao Y, Li X, Cai M, Wang H, Zhuang H, Tan M, Liu S, Hao Y and Lin B: Expression and clinical significance of annexin A2 and human epididymis protein 4 in endometrial carcinoma. J Exp Clin Cancer Res 34: 96, 2015

56. Alonso-Alconada L, Santacana M, Garcia-Sanz P, MuineloRomay L, Colas E, Mirantes C, Monge M, Cueva J, Oliva E, Soslow RA, et al: Annexin-A2 as predictor biomarker of recurrent disease in endometrial cancer. Int J Cancer 136: 1863-1873, 2015.

57. Zhang Q, Ye Z, Yang Q, He X, Wang H and Zhao Z: Upregulated expression of annexin II is a prognostic marker for patients with gastric cancer. World J Surg Oncol 10: 103, 2012.

58. Han Y, Ye J, Dong Y, Xu Z and Du Q: Expression and significance of annexin A2 in patients with gastric adenocarcinoma and the association with E-cadherin. Exp Ther Med 10: 549-554, 2015.

59. Gao H, Yu B, Yan Y, Shen J, Zhao S, Zhu J, Qin W and Gao Y: Correlation of expression levels of ANXA2, PGAM1, and CALR with glioma grade and prognosis. J Neurosurg 118: 846-853, 2013.

60. Onishi M, Ichikawa T, Kurozumi K, Inoue S, Maruo T, Otani Y, Fujii K, Ishida J, Shimazu Y, Yoshida K, et al: Annexin A2 regulates angiogenesis and invasion phenotypes of malignant glioma. Brain Tumor Pathol 32: 184-194, 2015.

61. Zhai H, Acharya S, Gravanis I, Mehmood S, Seidman RJ, Shroyer KR, Hajjar KA and Tsirka SE: Annexin A2 promotes glioma cell invasion and tumor progression. J Neurosci 31: 14346-14360, 2011.

62. Mohammad HS, Kurokohchi K, Yoneyama H, Tokuda M, Morishita A, Jian G, Shi L, Murota M, Tani J, Kato K, et al: Annexin A2 expression and phosphorylation are up-regulated in hepatocellular carcinoma. Int J Oncol 33: 1157-1163, 2008.

63. Bai DS, Wu C, Yang LX, Zhang C, Zhang PF, He YZ, Cai JB, Song ZJ, Dong ZR, Huang XY, et al: UBAP2 negatively regulates the invasion of hepatocellular carcinoma cell by ubiquitinating and degradating Annexin A2. Oncotarget 7: 32946-32955, 2016.

64. Zhang H, Yao M, Wu W, Qiu L, Sai W, Yang J, Zheng W, Huang J and Yao D: Up-regulation of annexin A2 expression predicates advanced clinicopathological features and poor prognosis in hepatocellular carcinoma. Tumour Biol 36: 9373-9383, 2015.

65. Zhang HJ, Yao DF, Yao M, Huang H, Wang L, Yan MJ, Yan XD, Gu X, Wu W and Lu SL: Annexin A2 silencing inhibits invasion, migration, and tumorigenic potential of hepatoma cells. World J Gastroenterol 19: 3792-3801, 2013.

66. Zhang HJ, Yao DF, Yao M, Huang H, Wu W, Yan MJ, Yan XD and Chen J: Expression characteristics and diagnostic value of annexin A2 in hepatocellular carcinoma. World J Gastroenterol 18: 5897-5904, 2012.

67. Cui HY, Wang SJ, Miao JY, Fu ZG, Feng F, Wu J, Yang XM, Chen ZN and Jiang JL: CD147 regulates cancer migration via direct interaction with Annexin A2 and DOCK3- $\beta$-cateninWAVE2 signaling. Oncotarget 7: 5613-5629, 2016.

68. Dong Z, Yao M, Zhang H, Wang L, Huang H, Yan M, Wu W and Yao D: Inhibition of Annexin A2 gene transcription is a promising molecular target for hepatoma cell proliferation and metastasis. Oncol Lett 7: 28-34, 2014
69. Sun Y, Gao G, Cai J, Wang Y, Qu X, He L, Liu F, Zhang Y, Lin K, Ma S, et al: Annexin A2 is a discriminative serological candidate in early hepatocellular carcinoma. Carcinogenesis 34: 595-604, 2013.

70. Wang YX, Lv H, Li ZX, Li C and Wu XY: Effect of shRNA mediated down-regulation of Annexin A2 on biological behavior of human lung adencarcinoma cells A549. Pathol Oncol Res 18: 183-190, 2012

71. Jia JW, Li KL, Wu JX and Guo SL: Clinical significance of annexin II expression in human non-small cell lung cancer. Tumour Biol 34: 1767-1771, 2013.

72. Luo CH, Liu QQ, Zhang PF, Li MY, Chen ZC and Liu YF: Prognostic significance of annexin II expression in non-small cell lung cancer. Clin Transl Oncol 15: 938-946, 2013.

73. Cole SP, Pinkoski MJ, Bhardwaj G and Deeley RG: Elevated expression of annexin II (lipocortin II, p36) in a multidrug resistant small cell lung cancer cell line. Br J Cancer 65: 498-502, 1992.

74. Bao H, Jiang M, Zhu M, Sheng F, Ruan J and Ruan C: Overexpression of Annexin II affects the proliferation, apoptosis, invasion and production of proangiogenic factors in multiple myeloma. Int J Hematol 90: 177-185, 2009.

75. Lokman NA, Pyragius CE, Ruszkiewicz A, Oehler MK and Ricciardelli C: Annexin A2 and S100A10 are independent predictors of serous ovarian cancer outcome. Transl Res 171: 83-95.e2, 2016.

76. Deng Y, Chen C, Hua M, Xi Q, Liu R, Yang S, Liu J, Zhong J, Tang M, Lu S, et al: Annexin A2 plays a critical role in epithelial ovarian cancer. Arch Gynecol Obstet 292: 175-182, 2015.

77. Lokman NA, Elder AS, Ween MP, Pyragius CE, Hoffmann P, Oehler MK and Ricciardelli C: Annexin A2 is regulated by ovarian cancer-peritoneal cell interactions and promotes metastasis. Oncotarget 4: 1199-1211, 2013.

78. Pi F, Zhang H, Li H, Thiviyanathan V, Gorenstein DG, Sood AK and Guo P: RNA nanoparticles harboring annexin A2 aptamer can target ovarian cancer for tumor-specific doxorubicin delivery. Nanomedicine 13: 1183-1193, 2016.

79. Foley K, Rucki AA, Xiao Q, Zhou D, Leubner A, Mo G, Kleponis J, Wu AA, Sharma R, Jiang Q, et al: Semaphorin 3D autocrine signaling mediates the metastatic role of annexin A2 in pancreatic cancer. Sci Signal 8: ra77-ra77, 2015.

80. Zheng L, Foley K, Huang L, Leubner A, Mo G, Olino K, Edil BH, Mizuma M, Sharma R, Le DT, et al: Tyrosine 23 phosphorylation-dependent cell-surface localization of annexin A2 is required for invasion and metastases of pancreatic cancer. PLoS One 6: e19390, 2011.

81. Nedjadi T, Kitteringham N, Campbell F, Jenkins RE, Park BK, Navarro P, Ashcroft F, Tepikin A, Neoptolemos JP and Costello E: S100A6 binds to annexin 2 in pancreatic cancer cells and promotes pancreatic cancer cell motility. Br J Cancer 101: 1145-1154, 2009.

82. Huang YK, Liu H, Wang XZ and Zhu S: Annexin A2 and CD105 expression in pancreatic ductal adenocarcinoma is associated with tumor recurrence and prognosis. Asian Pac J Cancer Prev 15: 9921-9926, 2014

83. Jung H, Kim JS, Kim WK, Oh KJ, Kim JM, Lee HJ, Han BS, Kim DS, Seo YS, Lee SC, et al: Intracellular annexin A2 regulates $\mathrm{NF}-\kappa \mathrm{B}$ signaling by binding to the $\mathrm{p} 50$ subunit: Implications for gemcitabine resistance in pancreatic cancer. Cell Death Dis 6: e1606, 2015.

84. Takano S, Togawa A, Yoshitomi H, Shida T, Kimura F, Shimizu H, Yoshidome H, Ohtsuka M, Kato A, Tomonaga T, et al: Annexin II overexpression predicts rapid recurrence after surgery in pancreatic cancer patients undergoing gemcitabineadjuvant chemotherapy. Ann Surg Oncol 15: 3157-3168, 2008.

85. Zheng L and Jaffee EM: Annexin A2 is a new antigenic target for pancreatic cancer immunotherapy. OncoImmunology 1: 112-114, 2012.

86. Keklikoglou I, Hosaka K, Bender C, Bott A, Koerner C, Mitra D, Will R, Woerner A, Muenstermann E, Wilhelm H, et al: MicroRNA-206 functions as a pleiotropic modulator of cell proliferation, invasion and lymphangiogenesis in pancreatic adenocarcinoma by targeting ANXA2 and KRAS genes. Oncogene 34: 4867-4878, 2015.

87. Zhang Q, Zhao Z, Ma Y, Wang H, Ma J, He X and Zhang D: Combined expression of S100A4 and Annexin A2 predicts disease progression and overall survival in patients with urothelial carcinoma. Urol Oncol 32: 798-805, 2014. 
88. Feng JG, Liu Q, Qin X, Geng YH, Zheng ST, Liu T, Sheyhidin I and Lu XM: Clinicopathological pattern and Annexin A2 and Cdc42 status in patients presenting with differentiation and lymphnode metastasis of esophageal squamous cell carcinomas. Mol Biol Rep 39: 1267-1274, 2012.

89. Li X, Zheng S, Liu Q, Liu T, Liang M, Gao X, Lu M, Sheyhidin I and $\mathrm{Lu} \mathrm{X}$ : Under-expression of annexin A2 is associated with Kazakh's esophageal squamous cell carcinoma. Mol Carcinog 54: 779-788, 2015.

90. Rodrigo Tapia JP, Pena Alonso E, García-Pedrero JM, Florentino Fresno M, Suárez Nieto C, Owen Morgan R and Fernández MP: Annexin A2 expression in head and neck squamous cell carcinoma. Acta Otorrinolaringol Esp 58: 257-262, 2007 (In Spanish)

91. Yee DS, Narula N, Ramzy I, Boker J, Ahlering TE, Skarecky DW and Ornstein DK: Reduced annexin II protein expression in highgrade prostatic intraepithelial neoplasia and prostate cancer. Arch Pathol Lab Med 131: 902-908, 2007.

92. Ding T, Yang L, Wang Y, Yuan J, Chen T and Cai X: Downregulation of annexin II in prostate cancer is associated with Gleason score, recurrence, metastasis and poor prognosis. Mol Med Rep 3: 781-787, 2010.

93. Smitherman AB, Mohler JL, Maygarden SJ and Ornstein DK: Expression of annexin I, II and VII proteins in androgen stimulated and recurrent prostate cancer. J Urol 171: 916-920, 2004.
94. Sharma M, Blackman MR and Sharma MC: Antibody-directed neutralization of annexin II (ANX II) inhibits neoangiogenesis and human breast tumor growth in a xenograft model. Exp Mol Pathol 92: 175-184, 2012.

95. Singh $\mathrm{P}, \mathrm{Wu} \mathrm{H}, \mathrm{Clark} \mathrm{C}$ and Owlia A: Annexin II binds progastrin and gastrin-like peptides, and mediates growth factor effects of autocrine and exogenous gastrins on colon cancer and intestinal epithelial cells. Oncogene 26: 425-440, 2007.

96. Reeves SA, Chavez-Kappel C, Davis R, Rosenblum M and Israel MA: Developmental regulation of annexin II (Lipocortin 2) in human brain and expression in high grade glioma. Cancer Res 52: 6871-6876, 1992.

97. Zhong LP, Wei KJ, Yang X, Zhang L, Zhou XJ, Pan HY, Li J, Chen WT and Zhang ZY: Increased expression of Annexin A2 in oral squamous cell carcinoma. Arch Oral Biol 54: 17-25, 2009.

98. Sharma MC, Tuszynski GP, Blackman MR and Sharma M: Long-term efficacy and downstream mechanism of antiannexinA2 monoclonal antibody (anti-ANX A2 mAb) in a pre-clinical model of aggressive human breast cancer. Cancer Lett 373: 27-35, 2016. 